\title{
Optical Switch Performance for Electronic Applications
}

\author{
V.Reji ${ }^{\text {a,1 }}$, Bhavadharani N ${ }^{\text {a }}$, Shridhar.B ${ }^{\text {a }}$, K.Chaitra Sri ${ }^{\text {a }}$ \\ ${ }^{a}$ SRM Institute of Science and Technology, Chennai, Tamil Nadu, India
}

\begin{abstract}
In this paper, various optically controlled switch performances are studied and analysed. Different types of optically controlled materials are considered in this paper to control the electrical frequency with a modified and simpler structure. Roger and Fr-4 materials are used as substrate material for the basic system design with the dielectric constant of 3.0 and 4.4 respectively. Materials like silicon, germanium, graphene, and polymers are considered for analysis in the proposed system and the semiconductor metals are etched in the middle of the copper strip. The thickness of the copper is $0.008 \mathrm{~mm}$ with the standard conductivity of $5.814 \mathrm{e} 7 \mathrm{~S} / \mathrm{m}$ and the length and width of the copper strip are $2.54 \times 2.54 \mathrm{~mm}$.A Copper strip is printed on the substrate to test the performance of the switches. The operating frequency of the given optical signal of silicon is around $1 \mathrm{GHz}$ to $25 \mathrm{GHz}$, graphene is around $1 \mathrm{GHz}$ to $30 \mathrm{GHz}$, germanium is around $1 \mathrm{GHz}$ to $30 \mathrm{GHz}$ and polymer is around $1 \mathrm{GHz}$ to $25 \mathrm{GHz}$. The $\mathrm{S} 11$ parameter of all the proposed systems is analysed by sonnet simulation software.
\end{abstract}

Keywords. Silicon, Germanium, Substrate, Polymer, Semiconductor

\section{Introduction}

Many kinds of research are being made in recent days to produce highly effective switches with several materials and methods [1]. Illuminated optical controlled GCPW switch has been designed with low insertion loss up to $50 \mathrm{GHz}$ with induced plasmas [2] and a QPSK model has been demonstrated for transverse electric polarization with 4*4 DLN non-blocking silicon switch for optical circuit and packet switching [3]. Another micro fluid switch with compressed micro fluid channels has been developed in [4] for better conductivity. Doherty power amplifier and frequency tuning turntable mechanism have been developed at 1.8 to $3.4 \mathrm{GHz}$ for power amplification and matching networks [5].Graphene oxide with dispersed hydrogen bond liquid crystal was used for optical switching and optical and electrical properties are achieved by etching dry crystalline silicon with solar cell by short circuiting with extraordinary output and storage [6]. Hydrolation wave spectrometer using telecom with heterodyne detection using $\mathrm{THz}$ measures the phase delay result from a single sheet of paper alternatively a resonance cavity has been used in [7] with increased sensitivity.

\footnotetext{
${ }^{1}$ V.Reji, SRM Institute of Science and Technology, Chennai, Tamil Nadu, India; Email: rejiv@srmist.edu.in.
} 
The proposed system compares the optical performance of semiconductors and polymers in the electrical domain. This study is useful for developing a switch or sensor that should be operated in both the electrical and optical domains. The aim of our project is to make a small optically controlled electrical switch model with different semiconductor metals and polymers and analyse their performance.

\section{Basic design and materials}

The basic design consists of a substrate, a strip with a switch design on the top, and infinite ground in the bottom [8-10]. The bottom ground and top layer are made up of copper material with a standard thickness of $1.6 \mathrm{~mm}$ and a conductivity of $5.814 \mathrm{e} 7 \mathrm{~S} / \mathrm{m}$. Two strip of copper films are placed on the substrate. In Between these copper films, semiconductors such as silicon, germanium, UV-polymer, and graphene are placed and simulated as shown in figure 1.

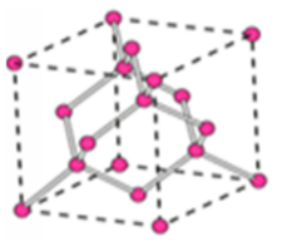

(a)

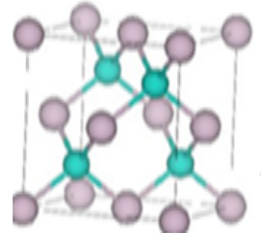

(b)

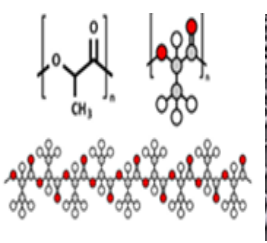

(c)

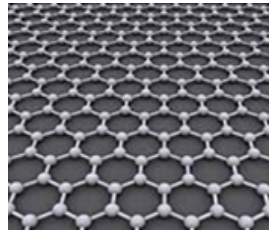

(d)

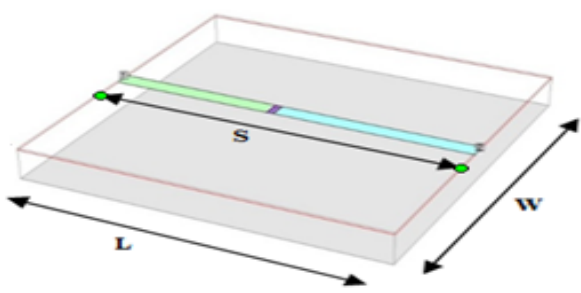

(e)

Figure 1. Semiconductors (a)Silicon (b)Germanium(c) Polymer(d)graphene (e)Basic Design( $L=200$ miles , $W=200$ miles,$S=200$ miles )

\section{Results and Discussion}

\subsection{Simulation with silicon switch}

Silicon switch is placed in between two copper plates as shown in Figure 2.The overall structure is printed on the Fr-4 and Roger substrate is shown in Figure 2. A copper thickness of $0.03 \mathrm{~mm}$ and conductivity of $5.8 \mathrm{e}^{6} \mathrm{~S} / \mathrm{m}$ and the thickness of silicon is $0.5 \mathrm{~mm}$ and conductivity $4.35 \mathrm{e}^{-3} \mathrm{~S} / \mathrm{m}$ is selected. It is clearly shown that in Figure 3 , the performance of switch with silver coating is nearly $-10 \mathrm{~dB}$ from $1 \mathrm{GHz}$ to $30 \mathrm{GHz}$ and the performance of aluminum coating is nearly $-6 \mathrm{~dB}$ from $1 \mathrm{GHz}$ to $35 \mathrm{GHz}$ for roger substrate at $850 \mathrm{~nm}$ optical signal(room temperature). But in Fr-4 substrate the 
conductivity of switch is reduced in high frequency ranges. It can be given a stable output from $1 \mathrm{GHz}$ to $20 \mathrm{GHz}$ as shown in Figure 4.
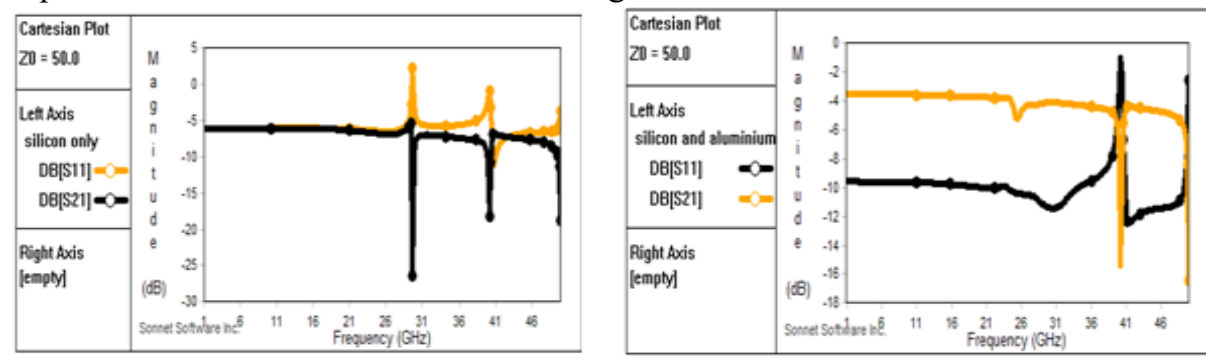

Figure 2. S11 Parameter of silicon switch on roger substrate (conductivity: $4.35 \mathrm{e}^{-3}$. Left - aluminum, Right silver)

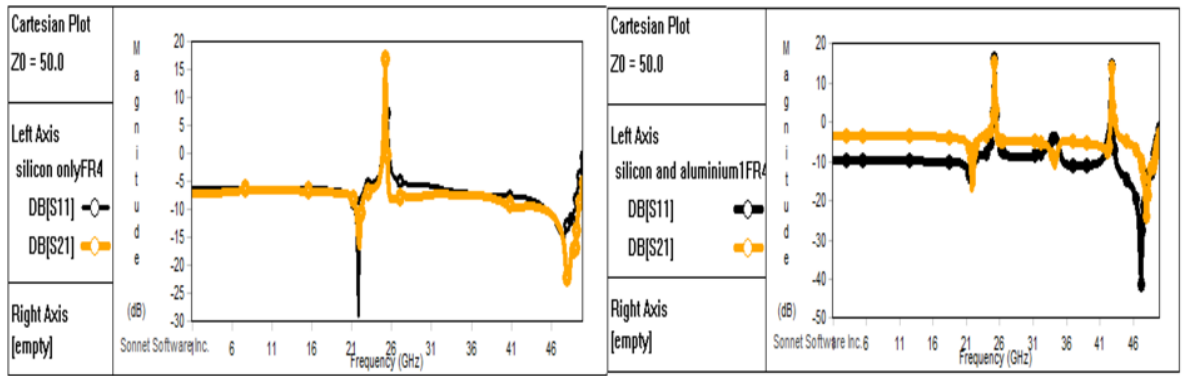

Figure 3. S11 Parameter of silicon switch on Fr-4 substrate (Conductivity: $4.35 \mathrm{e}^{-3}$ Left - aluminum, Right silver)

\subsection{Simulation with polymer switch}

Figure 4 and 5 shown a simulation output of UV- polymer etched between a copper plate on Roger and Fr-4 substrate. The thickness of copper and their conductivity is same as above in all the simulations. The thickness of polymer is $0.508 \mathrm{~mm}$ and conductivity is $50 \mathrm{~S} / \mathrm{m}$. In this simulation a stable output of $-25 \mathrm{~dB}$ is getting from Fr-4 substrate at $1 \mathrm{GHz}$ to $10 \mathrm{GHz}$ range and $-50 \mathrm{~dB}$ is getting from Roger substrate at $1 \mathrm{GHz}$ to $45 \mathrm{GHz}$ range.
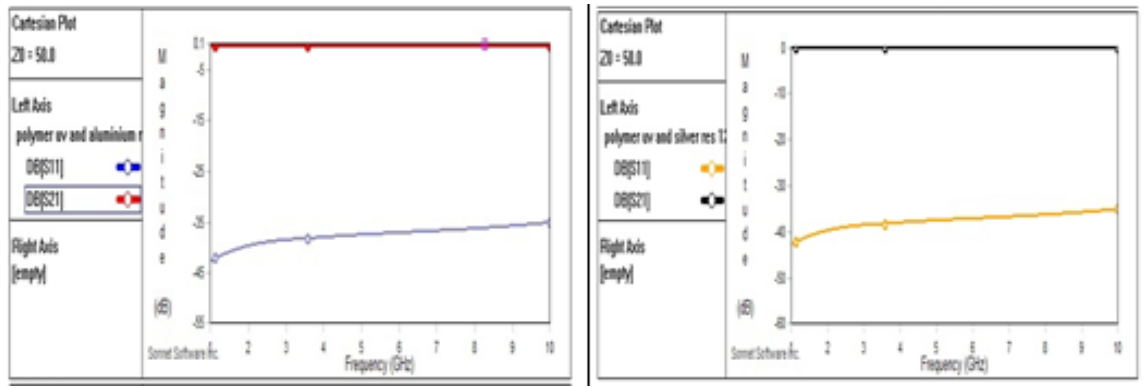

Figure 4. S11 Parameter of polymer switch on Fr-4 substrate (Conductivity:50 S/m -Left- aluminium, Right- silver) 


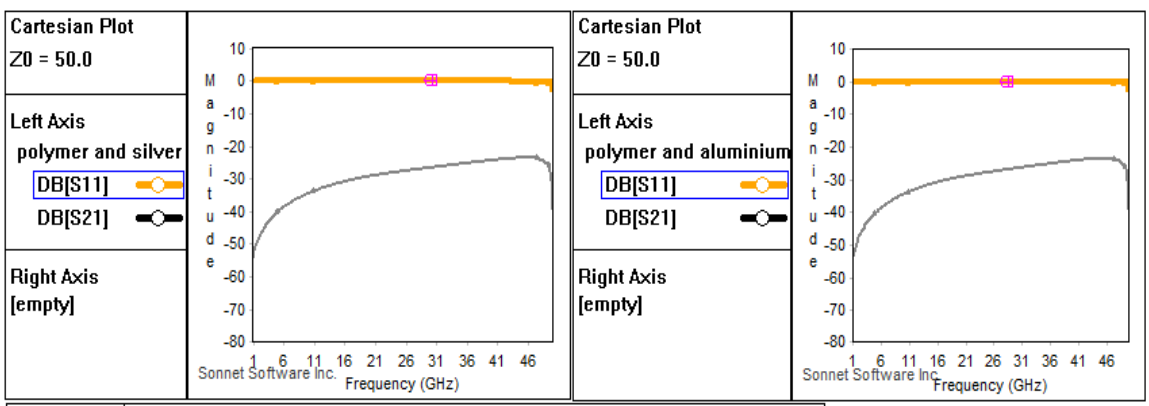

Figure 5. S11 Parameter of polymer switch on Roger substrate (Conductivity:50 S/m. Left- aluminium, Right- silver)

\subsection{Simulation with germanium}

Figure 6 shows a simulation of germanium is placed between the copper plate on the Roger and Fr-4 substrate are simulated. The selected thickness and conductivity of germanium is $0.5 \mathrm{~mm}$ and $1.54 \mathrm{e} 3 \mathrm{~S} / \mathrm{m}$ at $850 \mathrm{~nm}$ (room temperature) optical signal for simulation. It gives a maximum of $-15 \mathrm{~dB}$ return loss at $1 \mathrm{GHz}$ to $20 \mathrm{GHz}$ at Fr-4 substrate and $-20 \mathrm{~dB}$ return loss at $1 \mathrm{GHz}$ to $20 \mathrm{GHz}$ on Roger substrate with silver coating.

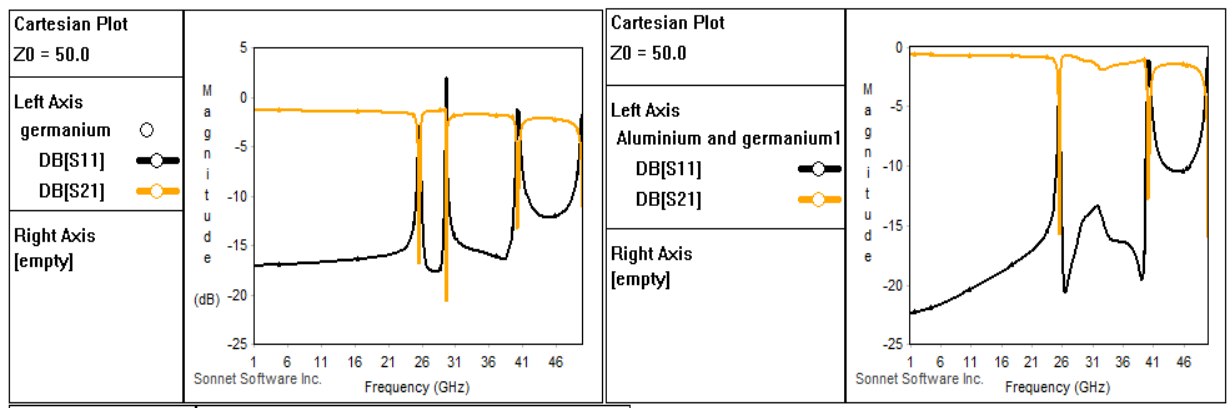

Figure 6. S11 Parameter of germanium switch on Fr-4 substrate (Conductivity:1.54 $\mathrm{e}^{3} \mathrm{~S} / \mathrm{m}$. Left- aluminium, Right -silver)

\subsection{Simulation with Graphene}

Figure 7 and 8 shows the simulation output of Graphene on Fr-4 and Roger substrate along with copper strip. Thickness and conductivity of the copper is $0.008 \mathrm{~mm}, 58.14 \mathrm{e}^{6}$ $\mathrm{S} / \mathrm{m}$ and the thickness and conductivity of the graphene is $0.3 \mathrm{~mm}, 10^{4}-10^{5} \mathrm{~S} / \mathrm{m}$ at $130 \mathrm{~nm}$. It shows an excellent performance in two substrate materials with a minimum return loss value of $-50 \mathrm{~dB}$. 

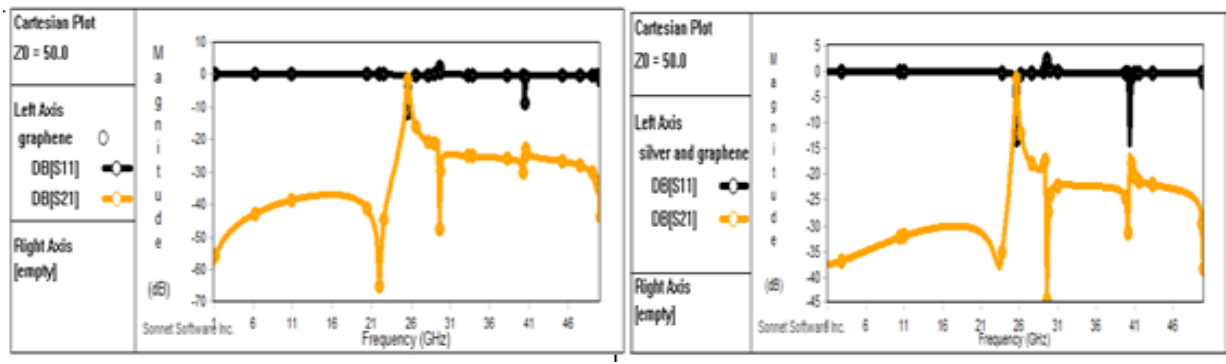

Figure 7. S11 Parameter of graphene switch on Fr-4 substrate (Conductivity: $10 \mathrm{e}^{4} \mathrm{~S} / \mathrm{m}$. Left- aluminum, Right- silver)
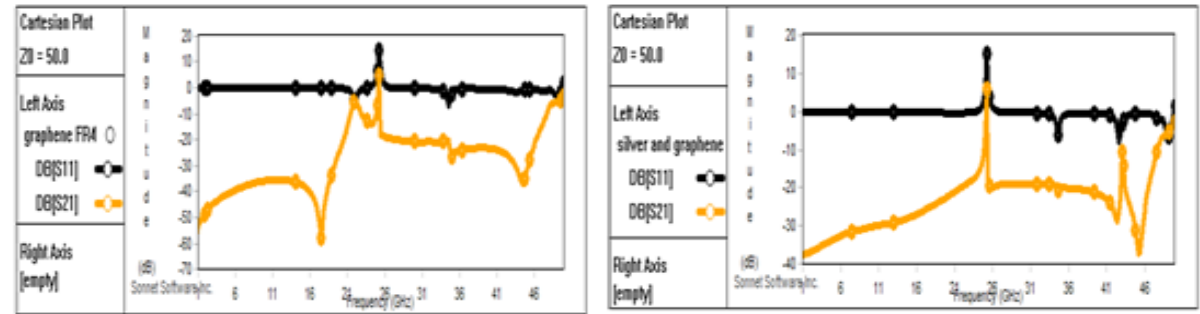

Figure 8. S11 Parameter of graphene switch on Roger substrate (Conductivity:10e ${ }^{4} \mathrm{~S} / \mathrm{m} . L e f t-$ aluminium, Right- silver)

\section{Conclusion}

The advantages of Graphene over other materials have boosted our interest. This highly strong yet thin and flexible material does not have an electronic band gap making it suitable to be a switch (it can switch between on and off). This encouraged us to explore its properties as a substitute for materials used for optical switches. On further study with the help of simulation shown us excellent results, however the manufacturing of Graphene is arduous and its usage is to be prevalent. Graphene is going to be a boon for the electronic domain in near the future. The above switching concept can be used for optically controlled frequency tuning reconfigurable antenna and filter circuits.

\section{References}

[1]. Pang, A. W., Gamlath, C. D., \& Cryan, M. J. (2018). An Optically Controlled Coplanar Waveguide Millimeter-Wave Switch. IEEE Microwave and Wireless Components Letters, 28(8), 669-671. https://doi.org/10.1109/LMWC.2018.2840966

[2]. [2]Lu, L., Li, X., Gao, W., Li, X., Zhou, L., \& Chen, J. (2019). Silicon Non-Blocking $4 \times 4$ Optical Switch Chip Integrated With Both Thermal and Electro-Optic Tuners. IEEE Photonics Journal, 11(6), 1-9. https://doi.org/10.1109/JPHOT.2019.2941960

[3]. Sikder, U., Usai, G., Yen, T.-T., Horace-Herron, K., Hutin, L., \& Liu, T.-J. K. (2020). Back-End-ofLine Nano-Electro-Mechanical Switches for Reconfigurable Interconnects. IEEE Electron Device Letters, 41(4), 625-628. https://doi.org/10.1109/LED.2020.2974473

[4]. Krstic, M., Eren, S., \& Jain, P. (2020). Analysis and Design of Multiphase, Reconfigurable SwitchedCapacitor Converters. IEEE Journal of Emerging and Selected Topics in Power Electronics, 8(4), 4046-4059. https://doi.org/10.1109/JESTPE.2019.2960016 
[5]. Jia, P., You, F., \& He, S. (2020). A 1.8-3.4-GHz Bandwidth-Improved Reconfigurable Mode Doherty Power Amplifier Utilizing Switches. IEEE Microwave and Wireless Components Letters, 30(1), 102105. https://doi.org/10.1109/LMWC.2019.2951215

[6]. Hindle, F., Shur, M., Abbot, D., \& Ozanyan, K. B. (2013). Guest Editorial THz Sensing: Materials, Devices, and Systems. IEEE Sensors Journal, 13(1), 7-7. https://doi.org/10.1109/JSEN.2012.2226647

[7]. Pal, K., Zhan, B., Ma, X., Madhu Mohan, M. L. N., \& Wang, G. (2016). Functionalized Graphene Oxide Dispersed Hydrogen Bonded Liquid Crystals Efficient Electro-Optical Switching. Journal of Display Technology, 12(3), 281-287. https://doi.org/10.1109/JDT.2015.2499326

[8]. Karanth, S. P., Sumesh, M. A., Shobha, V., Sirisha, J., Yadav M., D., Vijay, S. B., \& Sriram, K. V. (2020). Electro-Optical Performance Study of 4H-SiC/Pd Schottky UV Photodetector Array for Space Applications. IEEE Transactions on Electron Devices, 67(8), 3242-3249. https://doi.org/10.1109/TED.2020.3004306

[9]. Safdar, A., Wang, Y., Reardon, C., Li, J., de Arruda, G. S., Martins, A., Martins, E. R., \& Krauss, T. F. (2019). Interplay Between Optical and Electrical Properties of Nanostructured Surfaces in Crystalline Silicon Solar Cells. IEEE Photonics Journal, 11(4), 1-7. https://doi.org/10.1109/JPHOT.2019.2923562

[10]. Testa, F., Tondini, S., Gambini, F., Velha, P., Bianchi, A., Kopp, C., Hofbauer, M., Manganelli, C. L., Zecevic, N., Faralli, S., Pares, G., Enne, R., Serrano, A., Goll, B., Fontana, G., Chalyan, A., Lee, J.-M., Pintus, P., Chiaretti, G., ... Stracca, S. (2019). Integrated Reconfigurable Silicon Photonics Switch Matrix in IRIS Project: Technological Achievements and Experimental Results. Journal of Lightwave Technology, 37(2), 345-355. https://doi.org/10.1109/JLT.2018.2871974 